\title{
Geoprocessamento como ferramenta para a avaliação de áreas para a construção de aterros sanitários
}

GIS as a tool for the evaluation of areas for the construction of landfills

\author{
L. O. Carmo*; F. S. M. Nobre; D. P. Bitencurti
}

Núcleo de Engenharia Ambiental, Universidade Federal de Sergipe, 49100-000, São Cristóvão-Sergipe, Brasil

*laianeoc@gmail.com

(Recebido em 5 de fevereiro de 2016; aceito em 10 de junho de 2016)

A destinação adequada de resíduos sólidos tem sido uma preocupação frequente no Brasil, principalmente, depois de sancionada a Política Nacional de Resíduos Sólidos, que determina a substituição de lixões por aterros sanitários. Diante dessa preocupação, a implantação dos aterros sanitários tem como aliado importante, o geoprocessamento, que atua na prévia de escolha de região adequada ou na confirmação da mesma na construção de aterros. Nesse sentido, o presente trabalho tem como objetivo avaliar a adequabilidade das áreas que foram escolhidas para a construção dos aterros sanitários no Estado de Sergipe, utilizando principalmente, os dados de hidrografia, tipo e uso do solo das áreas de estudo sendo processados através do software AcGIS, versão 10.1. A partir dos resultados obtidos, observou-se uma irregularidade relacionada ao fato das sedes municipais em estudo estarem parcialmente inseridas no raio de $2000 \mathrm{~m}$ no entorno dos respectivos aterros sanitários, podendo ser um risco a saúde pública. Desse modo, conclui-se que o geoprocessamento é uma importante ferramenta no processo de avaliação da localização adequada para a construção de aterros sanitários e, consequentemente, contribui para a melhoria na qualidade ambiental e para a proteção da saúde pública.

Palavras-chave: avaliação, aterro sanitário, geoprocessamento.

The proper disposal of solid waste has been a frequent concern in Brazil, mainly after sanctioned the National Solid Waste Policy, which determines the replacement of garbage dump by landfill. Given this concern, the implementation of the landfill has an important ally, the geoprocessing, which operates in the prior choice of appropriate region or the confirmation of the same in the construction of landfills. Thereby, this study aims to evaluate the suitability of the areas that have been chosen for the construction of landfills in the state of Sergipe, using mainly the hydrography, type and land use data of the study areas that were processed by software AcGIS, version 10.1. From the results, it ocurred an irregularity related to the fact that headquarter of the cities studied are partially within the $2000 \mathrm{~m}$ radius surrounding the respective landfills, and it may be a risk for the public health. Thus, it is concluded that the geoprocessing is an important tool in the evaluation of suitable location for the construction of landfills, and consequently it contributes to the improvement in environmental quality and the protection of the public health.

Keywords: assessment, landfill, geoprocessing

\section{INTRODUÇÃO}

$\mathrm{O}$ aumento demasiado na densidade populacional do Brasil nas últimas décadas, provocou concomitantemente a este crescimento o aumento exponencial da quantidade de resíduos gerados pela população. De acordo com a estimativa do Programa da Organização das Nações Unidas para o Meio Ambiente (PNUMA), o volume de resíduos sólidos (lixo) urbanos produzido no mundo deve saltar de 1,3 bilhão de toneladas para 2,2 bilhões de toneladas até 2025 [12]. No Brasil, segundo a Associação Brasileira de Empresas de Limpeza Pública e Resíduos Especiais (ABRELPE), em 2012 foram descartados 24 milhões de toneladas de resíduos em lugares inadequados, além da geração de resíduos ter aumentado seis vezes mais do que a população em 2010 [1]; o que significa que, no último ano, cada brasileiro produziu sozinho uma média de $378 \mathrm{~kg}$ de resíduos sólidos.

No Brasil, a falta de políticas públicas eficazes que evidenciem a importância da separação do lixo e o seu descarte adequado contribuem para este cenário. Dessa forma, o material sólido na maioria das vezes é descartado juntamente com o lixo orgânico (responsável pelo chorume, substância altamente poluidora) e o lixo reciclável. Na perspectiva de destinação adequada para 
o lixo, de forma que minimize as agressões sofridas pelo meio ambiente e garantir a proteção à saúde pública, é que foram criados os aterros sanitários para a disposição final dos resíduos sólidos sem causar danos à saúde pública e ao meio ambiente; contribuindo para o desenvolvimento sustentável [6].

Partindo da premissa da importância da preservação do meio ambiente para uma melhor qualidade de vida, foi sancionada a Política Nacional de Resíduos Sólidos (Lei n ${ }^{0}$ 12.305, de 02 de agosto de 2010) [10], sendo determinado que em 2014 todos os lixões do país devem ser fechados e substituídos por aterros sanitários, que correspondem à uma melhor alternativa para a disposição de resíduos. Entretanto, de acordo com o Ministério do Meio Ambiente, 59\% dos municípios ainda destinam os resíduos sólidos aos lixões ou em aterros controlados [11]. Do mesmo modo, o estado de Sergipe necessita da construção de mais aterros sanitários para o alcance de todos os seus municípios.

Para a implantação de um aterro sanitário, no entanto, é necessário um estudo prévio sobre a área em que será construído e sua viabilidade, além de um planejamento e monitoramento quanto aos requisitos necessários para uma construção adequada, já que um aterro sanitário pode contribuir potencialmente com a poluição e contaminação do meio ambiente caso não tenha sido projetado e implantado de maneira viável [4]. Diante disso, o geoprocessamento apresenta-se como uma ferramenta de grande valia neste processo tanto na escolha da área a ser implantado, se baseando em normas técnicas e utilizando dados georreferenciados da área, quanto na análise da área do aterro previamente implantado.

Nesse sentido, o presente trabalho tem como objetivo reavaliar a adequabilidade da escolha dos locais destinados à implantação dos aterros sanitários do Polo de Gerenciamento de Resíduos Itacanema e do Centro de Gerenciamento de Resíduos Rosário do Catete, que são os únicos aterros sanitários existentes no estado de Sergipe, utilizando o geoprocessamento como ferramenta de análise.

\section{MATERIAL E MÉTODOS}

\section{1. Área de Estudo}

As áreas de estudo são os municípios de Maruim, Rosário do Catete e Nossa Senhora do Socorro, localizados no estado de Sergipe (Figura 1). Estas áreas foram selecionadas por conterem os dois aterros existentes no estado, que são o Polo de Gerenciamento de Resíduos Itacanema, localizado em Nossa Senhora do Socorro e o Centro de Gerenciamento de Resíduos Rosário do Catete, localizado em Rosário do Catete. Considerou-se o município de Maruim devido a sua proximidade com o Centro de Gerenciamento de Resíduos Rosário do Catete e para proporcionar uma melhor análise dos critérios utilizados para a escolha do local destinado aos aterros. 

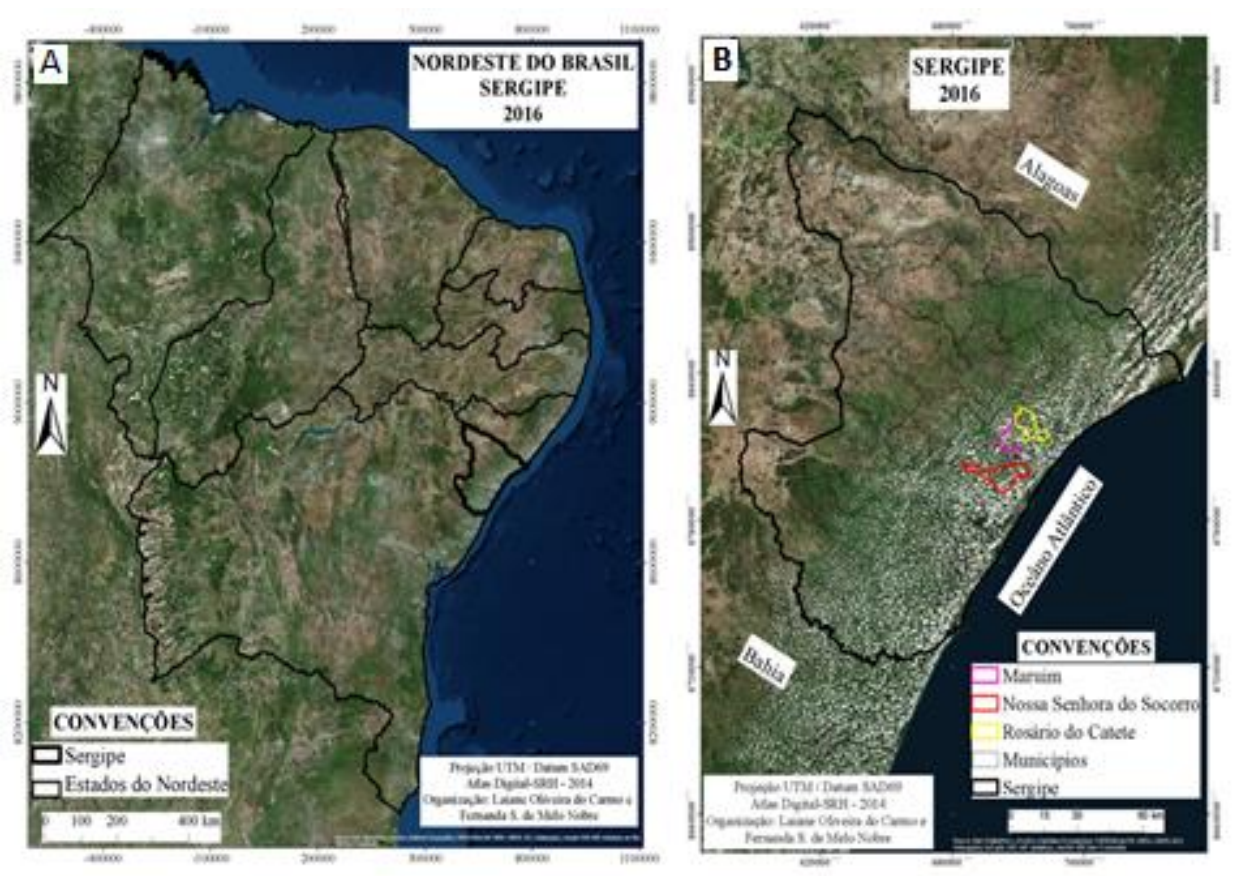

Figura 1: Região nordeste do Brasil com destaque para o estado de Sergipe (A) e os municípios estudados (B). Fonte: SRH e SEMARH (2014) [15].

De acordo com dados do IBGE (2015), estima-se que a população residente dos municípios de Nossa Senhora do Socorro e Rosário do Catete são de 177.344 e 10.364 habitantes e suas áreas territoriais são de $156,771 \mathrm{~km}^{2}$ e $105,660 \mathrm{~km}^{2}$, respectivamente [8]. As duas cidades encontram-se na porção leste do estado de Sergipe e são próximas da capital Aracaju, que possui uma das maiores populações do estado, ressaltando um dos critérios levados em conta para a escolha da implantação dos aterros.

Os municípios são caracterizados por apresentar tipos de solos similares, como se pode observar nas Figuras 2 e 3, com maior predomínio para os tipos de solos vertisol e podzólico vermelho amarelo em Rosário do Catete, halomórficos e podzólico vermelho amarelo em Maruim e podzólico vermelho amarelo em Nossa Senhora do Socorro.

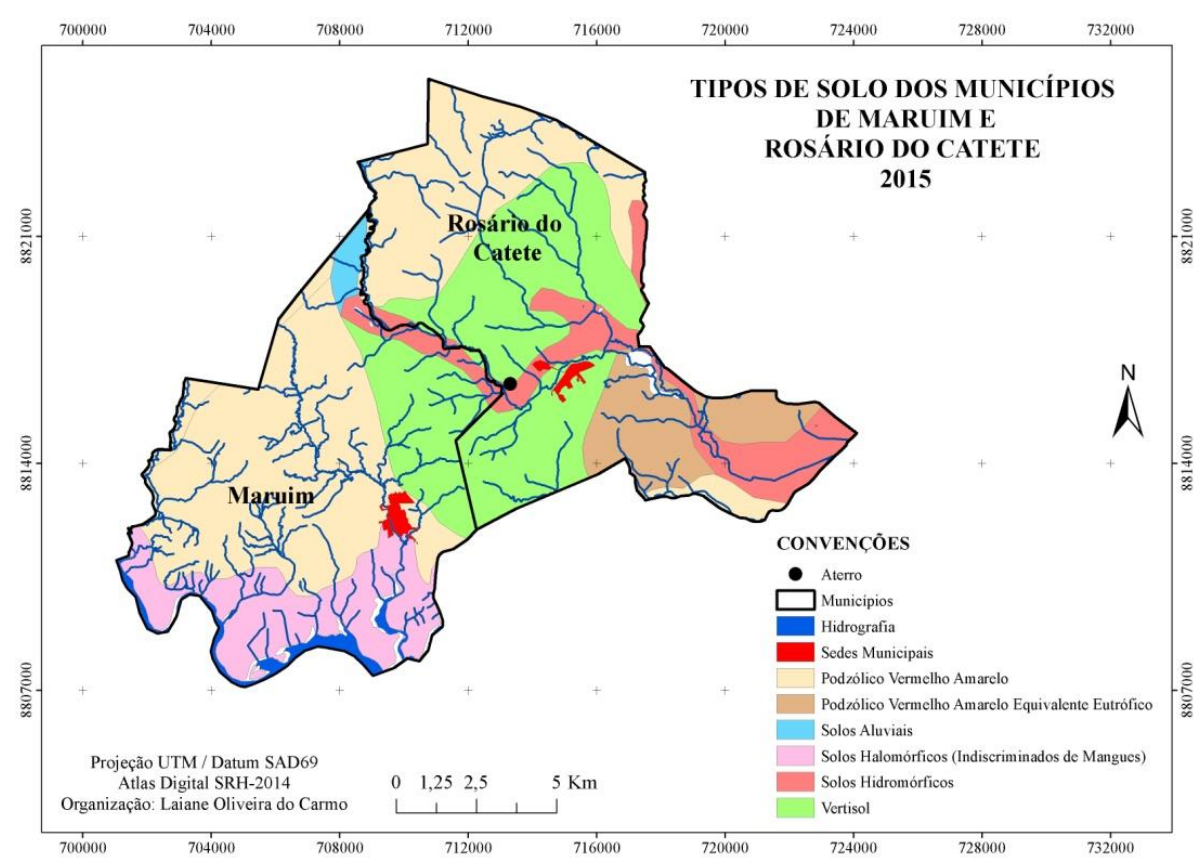

Figura 2: Mapa dos tipos de solos dos municípios de Maruim e de Rosário do Catete. Fonte: SRH e SEMARH (2014) [15]. 


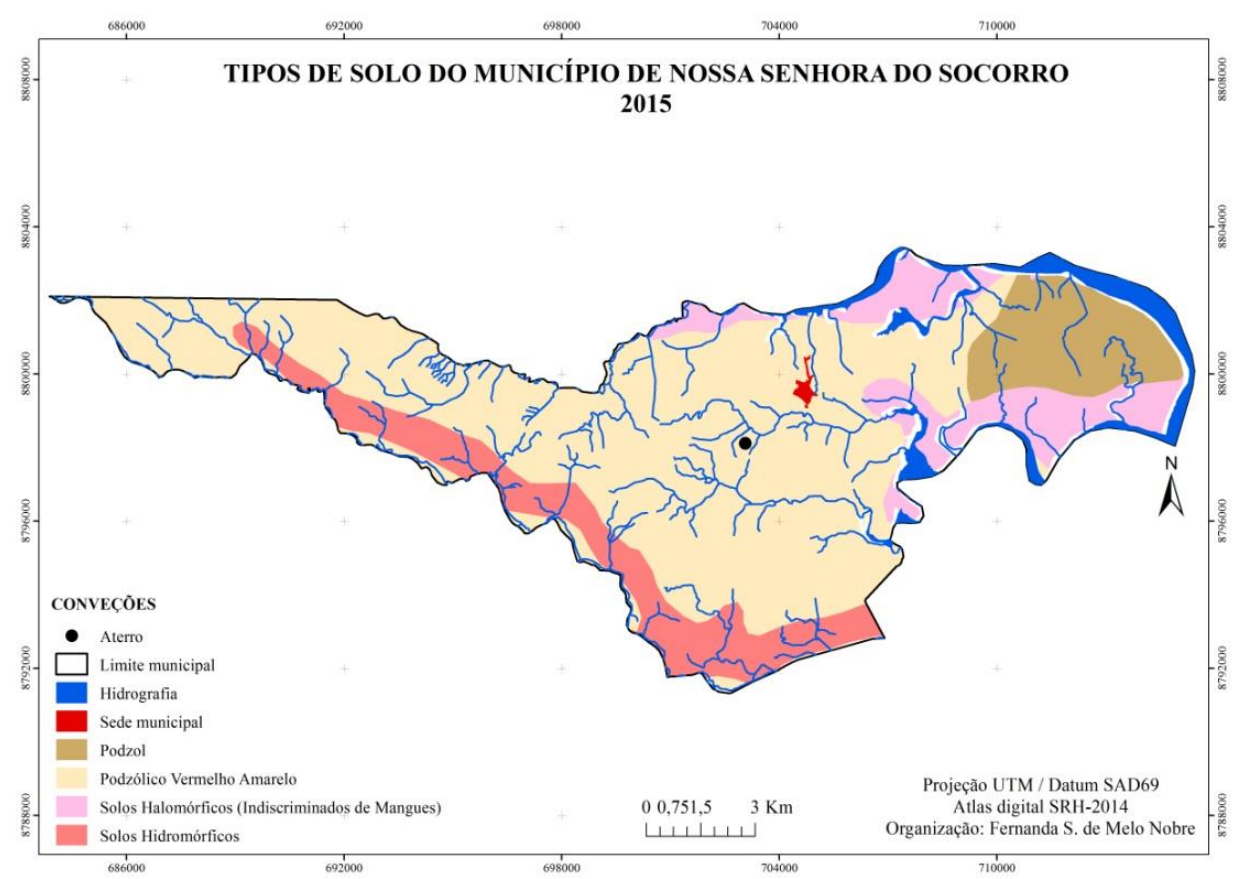

Figura 3: Mapa dos tipos de solos do município de Nossa Senhora do Socorro, Sergipe. Fonte: SRH e SEMARH (2014) [15].

Em relação ao uso o solo é possível constatar nos três municípios a predominância de pastagens, cultivos agrícolas e florestas estacionais. Nos municípios de Rosário do Catete e de Maruim destacam-se também a presença, respectivamente, de uma parcela de floresta ombrófila e de mangue, como é demostrado na Figura 4.

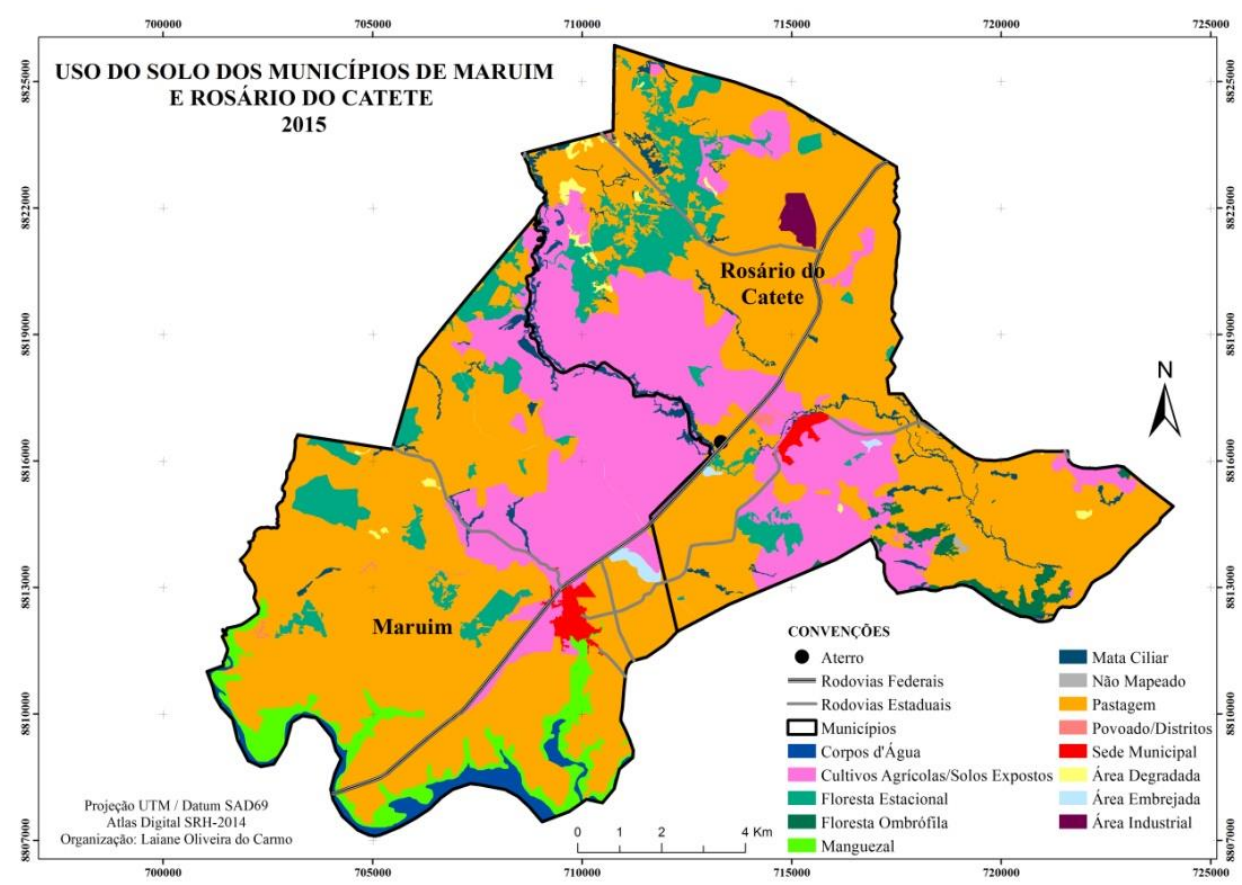

Figura 4: Mapa de uso de solo dos municípios de Maruim e de Rosário do Catete, Sergipe. Fonte: SRH e SEMARH (2014) [15].

Quanto ao município de Nossa Senhora do Socorro, este apresenta uma porção de manguezal ao leste do município. Vale ressaltar que há um erro de classificação no banco de dados do Atlas digital sobre recursos hídricos de Sergipe [15], que corresponde a uma base de dados georreferenciados que contém diversas informações sobre o estado de Sergipe como hidrografia, 
sedes municipais, tipo e uso do solo, dentre outros, que foram utilizados para o desenvolvimento do presente trabalho. O erro encontrado refere-se à identificação da sede municipal de Nossa Senhora do Socorro, pois outras feições estão representadas como sede municipal, incorrendo em erro na identificação dos mesmos. Sendo assim, a sede existente do município de Nossa Senhora do Socorro está contornada pelo círculo preto pontilhado, sendo apresentada na Figura 5 .

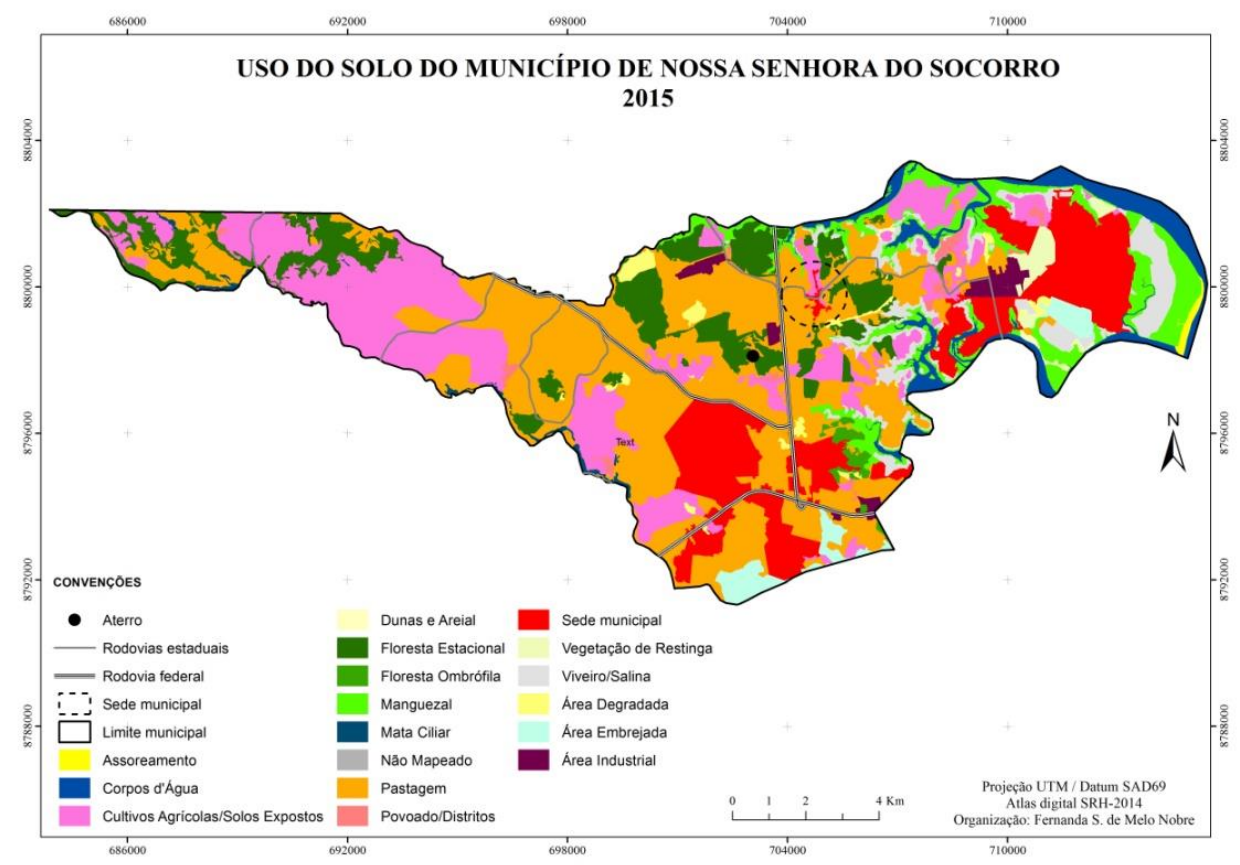

Figura 5: Mapa de uso de solo do município de Nossa Senhora do Socorro, Sergipe. Fonte: SRH e SEMARH (2014) [15].

O relevo das áreas de estudo varia de altitudes próximas ao nível do mar a aproximadamente de $140 \mathrm{~m}$, para os municípios de Maruim e Rosário do Catete, e de altitudes próximas ao nível do mar a aproximadamente $160 \mathrm{~m}$ para o município de Nossa Senhora do Socorro, como mostram os perfis aleatórios traçados e distribuídos sobre as imagens Shuttle Radar Topography Mission (SRTM) [7] na Figura 6, sendo caracterizadas como áreas de baixas altitudes. 


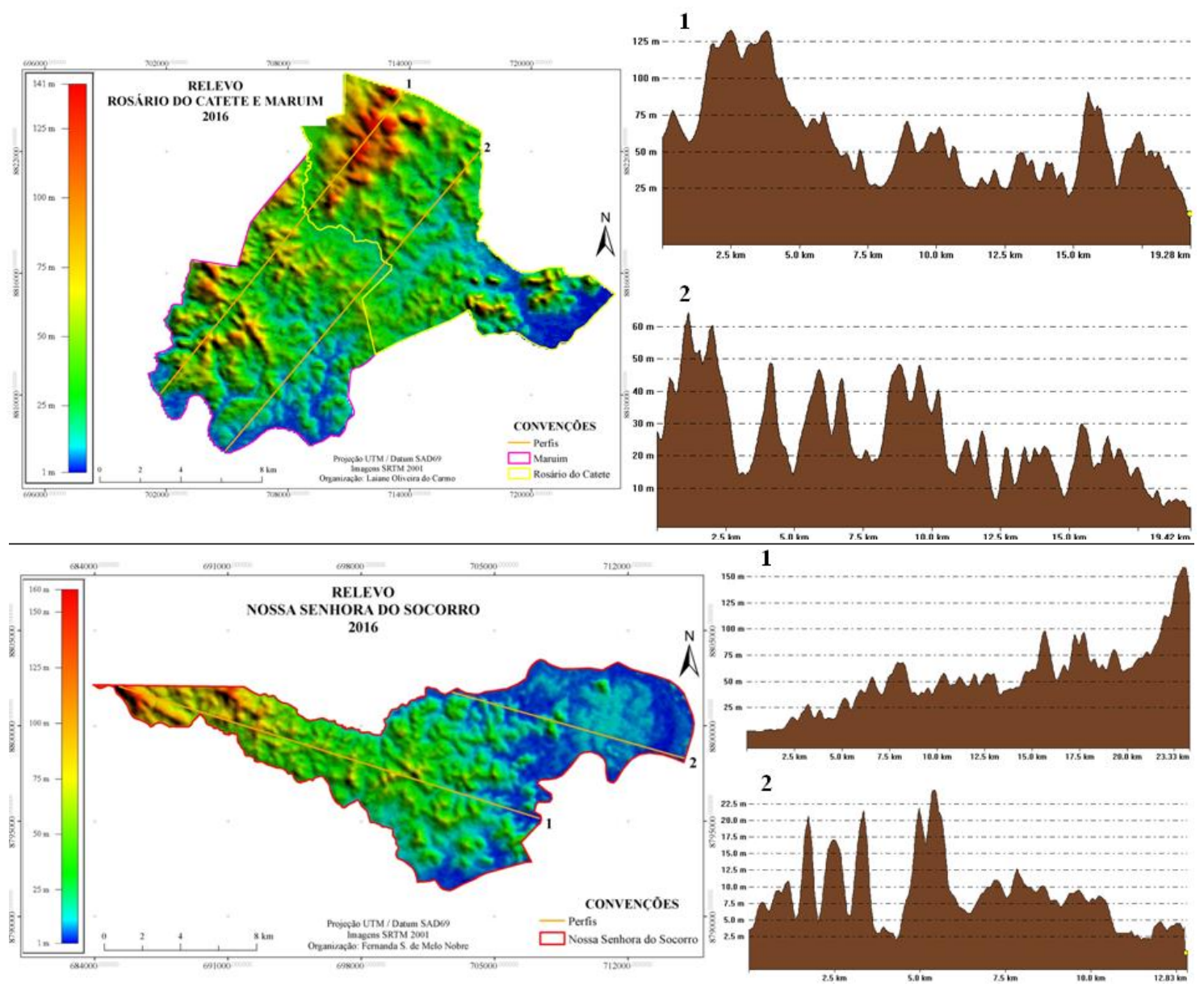

Figura 6: Relevo das áreas de estudo, mostrando os perfis de altitude dos municípios de Rosário do Catete, Maruim (acima) e de Nossa Senhora do Socorro (abaixo), em Sergipe. Fonte: Modificado de EMBRAPA (2015) [7].

\subsection{Aterros Sanitários}

O Centro de Gerenciamento de Resíduos Rosário do Catete (Figura 7) possui área de $1.500 .000 \mathrm{~m}^{2}$ e está regularmente licenciado pela Administração Estadual do Meio Ambiente (ADEMA), recebendo resíduos do referido município em que se encontra, além dos habitantes de diversos municípios circunvizinhos. Os resíduos dispostos no aterro são das classes I, II A e II B e, segundo a NBR 10.004 [2], são classificados em:

- Resíduos classe I - Perigosos: são aqueles que apresentam periculosidade e costumam apresentar características como: corrosividade, reatividade, inflamabilidade, toxicidade e patogenicidade;

- Resíduos classe II - Não perigosos:

○ Resíduos classe II A - Não inertes: são aqueles que não se enquadram nas classificações de resíduo classe I ou II B. Os resíduos classe II A - não inertes podem ter propriedades, tais como: combustibilidade, biodegradabilidade ou solubilidade em água.

- Resíduos classe II B - Inertes: quaisquer resíduos que em contato estático ou dinâmico com água destilada ou desionizada, a temperatura ambiente, não tiverem nenhum de seus constituintes solubilizados a concentrações superiores aos padrões de potabilidade de água. 


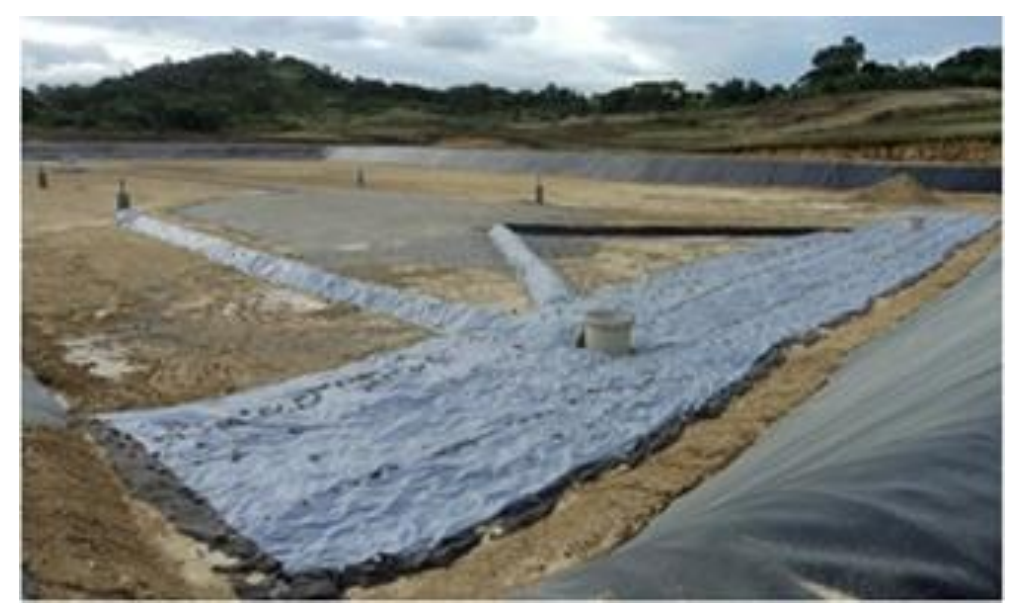

Figura 7: Centro de Gerenciamento de Resíduos Rosário do Catete, Sergipe. Fonte: Autor desconhecido [5].

Já o Polo de Gerenciamento de Resíduos Itacanema (Figura 8) apresenta uma capacidade de armazenamento de $5.412 .085 \mathrm{~m}^{3}$ de resíduos sólidos urbanos. Entretanto, este se encontra inativo após a suspenção da Licença de Instalação (LI) pelo Ministério Público Federal em Sergipe devido ao risco de contaminação do aquífero Sapucari existente na região. Entretanto, devido ao banco de dados do Atlas digital sobre recursos hídricos de Sergipe [15] apresentar este aterro como em operação, o mesmo foi mantido como área de estudo para confirmar a viabilidade de sua instalação.

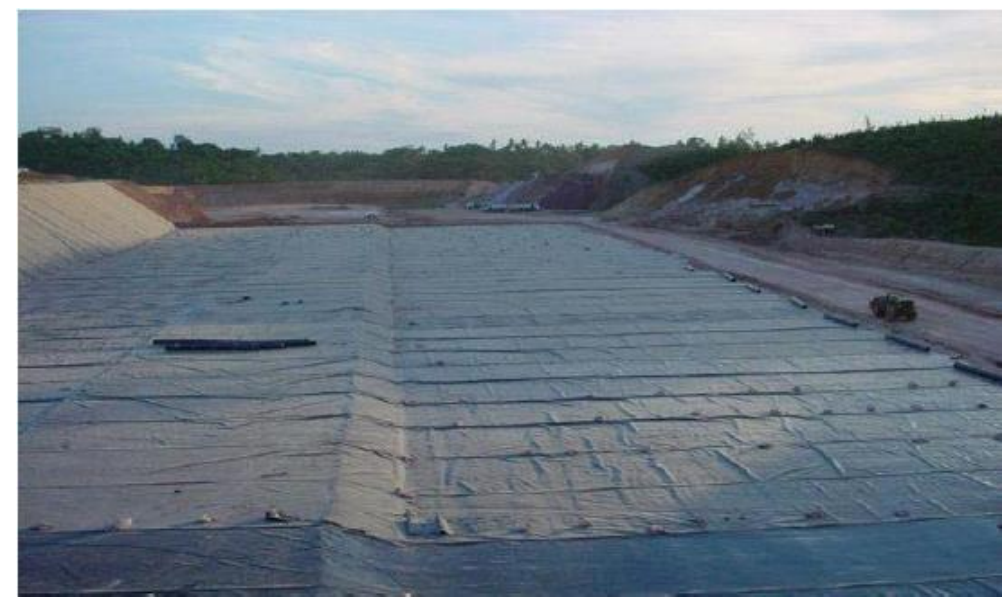

Figura 8: Polo de Gerenciamento de Resíduos Itacanema, Sergipe. Fonte: Autor desconhecido [13].

\subsection{Critérios Restritivos}

Os critérios restritivos básicos utilizados para avaliar a adequabilidade da seleção das áreas destinadas à instalação de aterros sanitários foram selecionados de acordo com critérios comumente descritos na literatura, sendo listados na Tabela 1.

Tabela 1: Critérios restritivos utilizados na avaliação da escolha da localização dos aterros sanitários

\begin{tabular}{|c|c|}
\hline Aspecto Técnico & Critério \\
\hline Distância mínima de corpos d'água* & $200 \mathrm{~m}$ \\
\hline Distância mínima de núcleos populacionais" & $500 \mathrm{~m}$ \\
\hline Distância mínima de áreas urbanas** & $2000 \mathrm{~m}$ \\
\hline Distância mínima das estradas*** & $300 \mathrm{~m}$ \\
\hline Tipo de solo ${ }^{* * *}$ & Argiloso \\
\hline Topografia* & $1 \%<$ declividade $<30 \%$ \\
\hline
\end{tabular}




\subsection{Mapas Temáticos}

A imagem utilizada no presente trabalho foi a imagem de satélite SPOT [15], que possui uma resolução espacial de 5 x 5 m, com Projeção UTM (Universal Transversor de Mercator) e datum SAD 69 (South American Datum 1969).

Inicialmente, utilizou-se software Global Mapper, versão 17, para realizar os recortes da imagem SPOT, restringindo-se aos limites de cada município em estudo. Além disso, foi utilizada a imagem Shuttle Radar Topography Mission (SRTM) [7] para a obtenção do detalhamento do relevo de cada município. Para isso, foram desenhadas duas linhas paralelas e aleatórias, gerando-se dois perfis de altitude em toda a extensão de cada município.

Em seguida, utilizou-se o software ArcGIS, versão 10.1, para interseccionar os limites dos municípios com seus respectivos dados de hidrografia, uso do solo, tipo de solo, sede municipais, estradas estaduais e federais, obtidos a partir do banco de dados do Atlas digital [15]. Além disso, utilizou-se a ferramenta buffer, criando áreas de medidas de 200, 500 e 2000 $\mathrm{m}$ ao redor dos aterros para a realização das análises em conjunto com os dados supracitados. Todos os mapas foram desenvolvidos por meio do uso deste mesmo programa, sendo exportados em formato .JPG.

\section{RESULTADOS E DISCUSSÃO}

A partir dos mapas gerados, considerando as características dos municípios e os critérios restritivos apresentados, foi possível avaliar a adequabilidade da seleção dos locais escolhidos para a instalação dos aterros sanitários em estudo.

Com base nos mapas de uso do solo dos municípios de Rosário do Catete, Maruim e de Nossa Senhora do Socorro, observou-se que os principais usos do solo no entorno do Centro de Gerenciamento de Resíduos Rosário do Catete (Figura 9) são pastagem, mata ciliar, área embrejada e cultivos agrícolas. Já nas áreas no entorno do Polo de Gerenciamento de Resíduos Itacanema (Figura 10), os principais usos são floresta estacional, cultivos agrícolas, área industrial e pastagem. Sendo assim, foi possível observar que nas áreas circunvizinhas aos aterros em estudos não apresentam núcleos populacionais num raio de $500 \mathrm{~m}$, atendendo ao critério de distanciamento requerido pela NBR 13.896 [3]. Além disso, evidenciou-se a proximidade de ambos os aterros em relação às rodovias estaduais, com distanciamentos menores que $300 \mathrm{~m}$, sendo este um dos fatores fundamentais para a escolha da localização dos aterros sanitários por contribuir, consideravelmente, para a diminuição dos custos referentes ao transporte dos resíduos desde as fontes até a sua destinação final. 


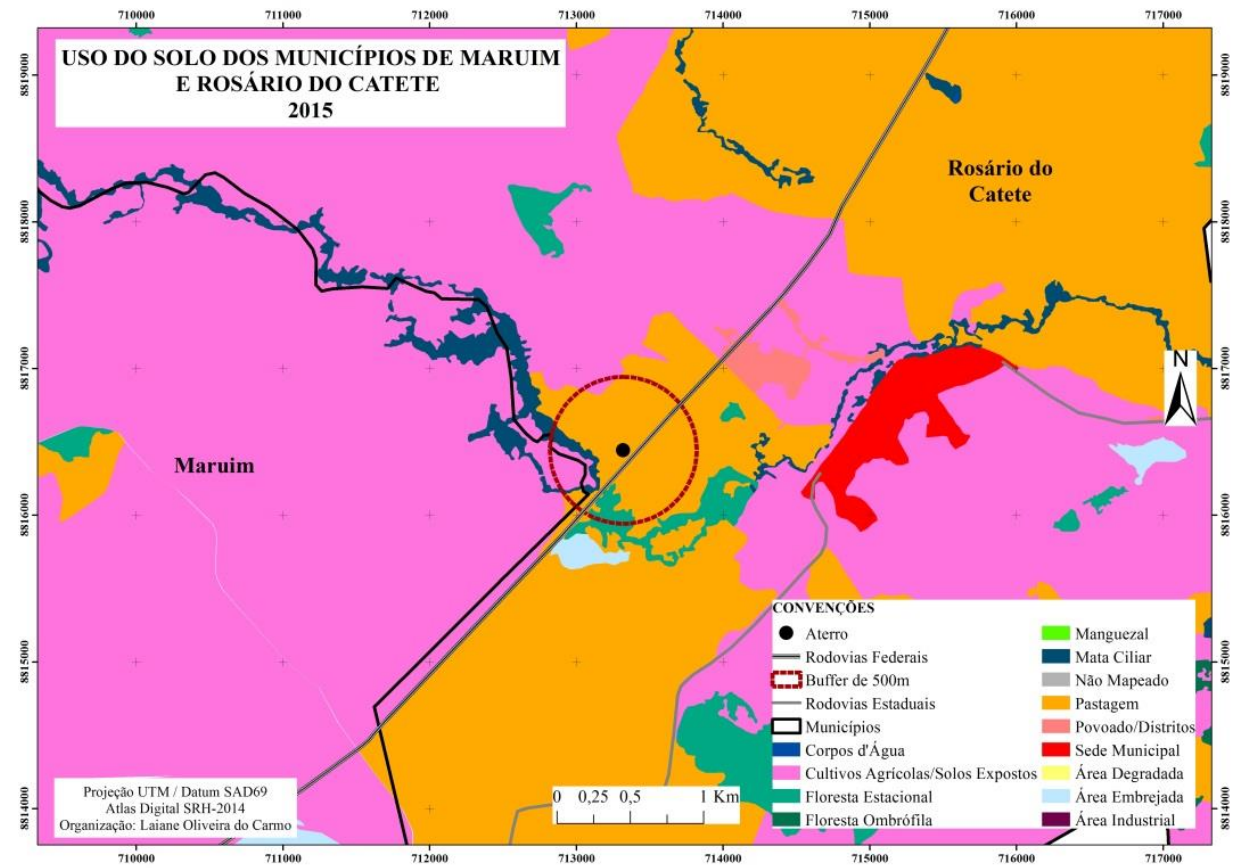

Figura 9: Mapa de uso do solo dos municípios de Rosário do Catete e de Maruim, Sergipe, destacando o buffer de $500 \mathrm{~m}$, que corresponde à distância mínima entre o aterro e núcleos populacionais, e vias de acesso através das rodovias estaduais e federais. Fonte: SRH e SEMARH (2014) [15].

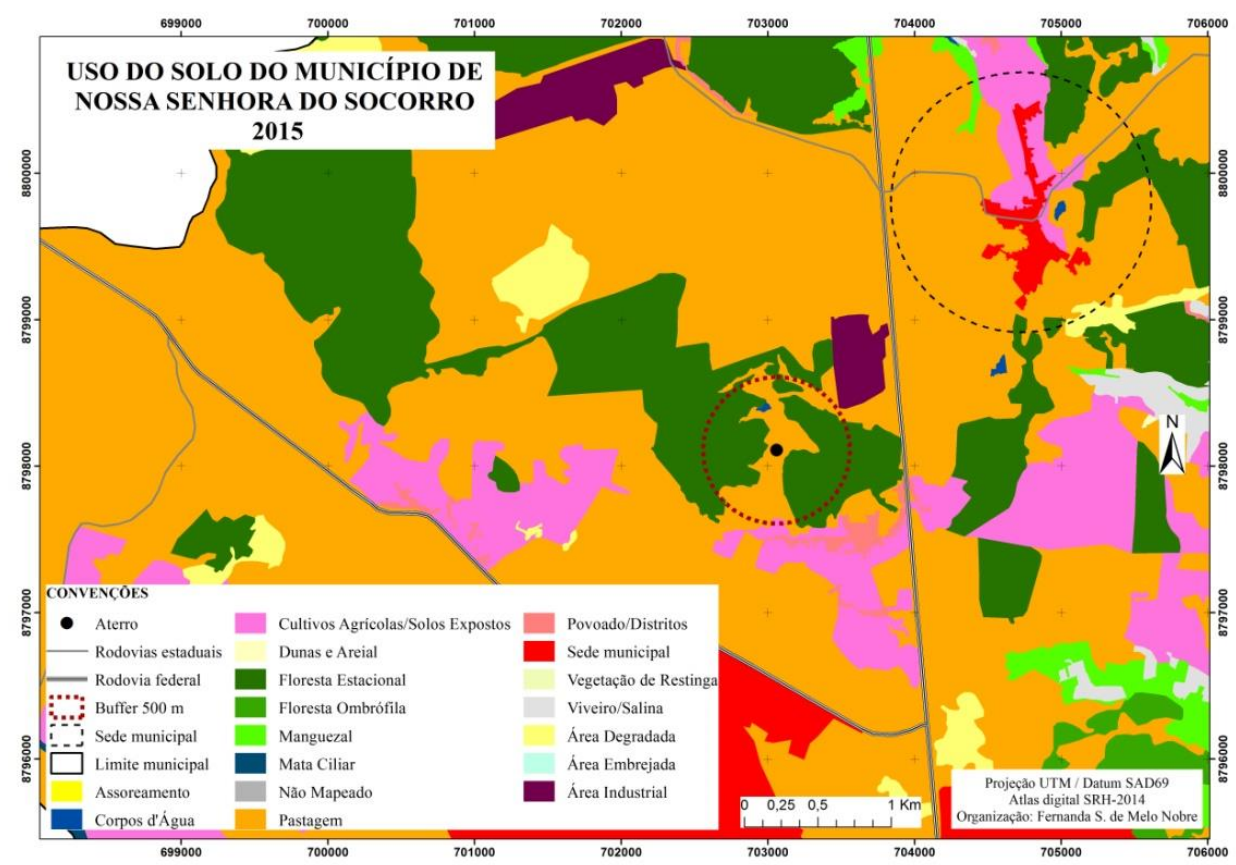

Figura 10: Mapa de uso do solo do município de Nossa Senhora do Socorro, Sergipe. destacando o buffer de $500 \mathrm{~m}$, que corresponde à distância mínima entre o aterro e núcleos populacionais, e vias de acesso através das rodovias estaduais e federais. Fonte: SRH e SEMARH (2014) [15].

Avaliando-se os mapas dos tipos de solos foi possível identificar que o tipo de solo predominante no entorno do aterro sanitário do Centro de Gerenciamento de Resíduos Rosário do Catete (Figura 11) e do Polo de Gerenciamento de Resíduos Itacanema (Figura 12) são, respectivamente, solos hidromórficos e podzólico vermelho amarelo. Os solos hidromórficos são constituídos por material mineral, apresentam má drenagem e, geralmente, ficam saturados em presença de água, contribuindo para o escoamento superficial. Já os podzólico vermelho amarelo, geralmente, são solos com baixa fertilidade e apresentam elevada porosidade e consequente baixa permeabilidade devido à presença de argilominerais [9]. Portanto, a 
localização dos aterros quanto aos tipos de solos, apresentam-se adequados para a inviabilização da percolação do chorume para os lençóis freáticos ou outras localidades.

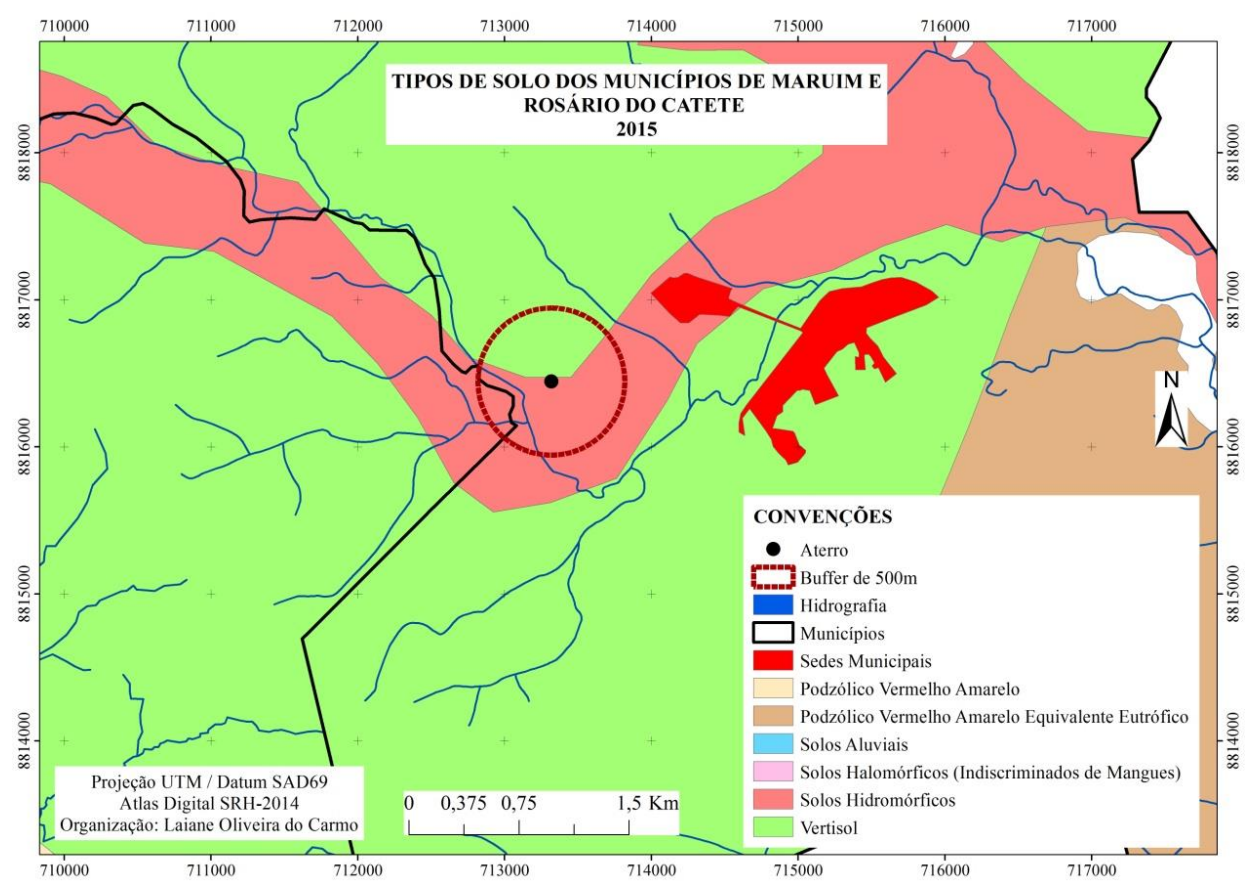

Figura 11: Mapa dos tipos de solos dos municípios de Rosário do Catete e de Maruim, Sergipe, destacando o buffer de $500 \mathrm{~m}$, que corresponde à distância mínima entre o aterro e núcleos populacionais, e a sede municipal. Fonte: SRH e SEMARH (2014) [15].

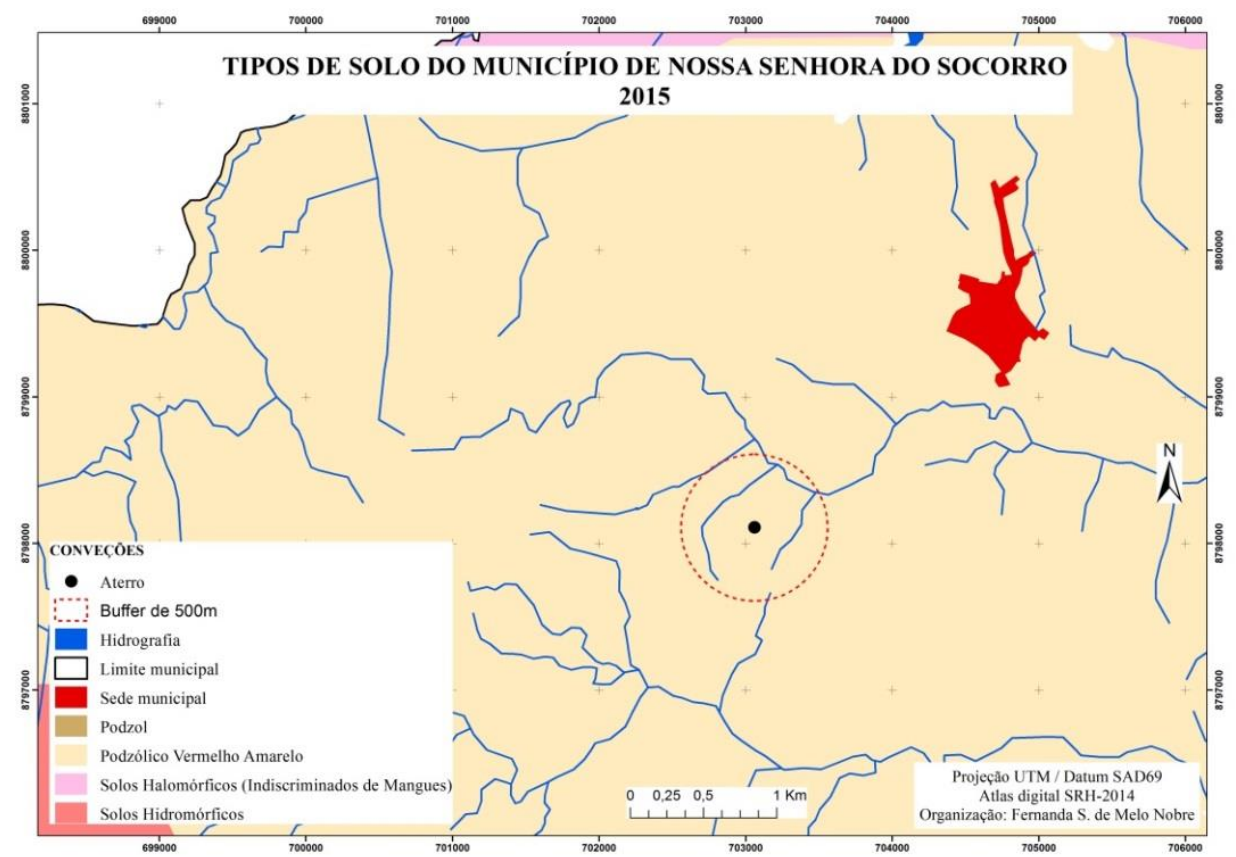

Figura 12: Mapa dos tipos de solos do município Nossa Senhora do Socorro, Sergipe, destacando o buffer de $500 \mathrm{~m}$, que corresponde à distância mínima entre o aterro e núcleos populacionais, e a sede municipal. Fonte: SRH e SEMARH (2014) [15].

Com base nos dados de hidrografia dos municípios de Rosário do Catete, Maruim e de Nossa Senhora do Socorro, constatou-se a presença de diversos corpos hídricos próximos aos aterros sanitários, porém estes se encontram a uma distância maior do que o raio de $200 \mathrm{~m}$ do entorno dos aterros sanitários em estudo, conforme as Figuras 13 e 14. Portanto, as localizações dos 
aterros sanitários estão adequadas quanto ao distanciamento de recursos hídricos, incluindo lagos e reservatórios.

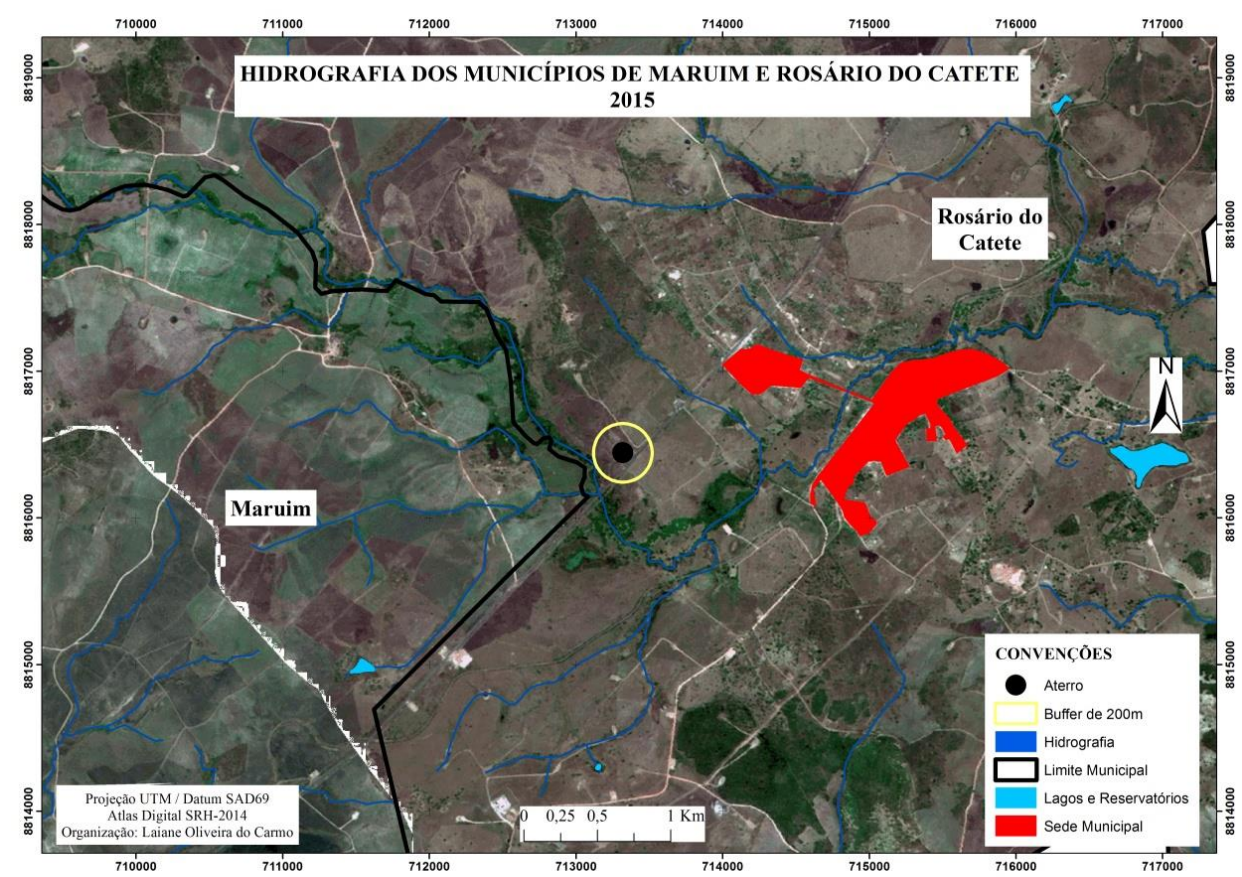

Figura 13: Mapa da hidrografia dos municípios de Rosário do Catete e de Maruim, Sergipe destacando o buffer de $200 \mathrm{~m}$ que corresponde ao limite mínimo entre o aterro e corpos d'água do seu entorno. Fonte: SRH e SEMARH (2014) [15].

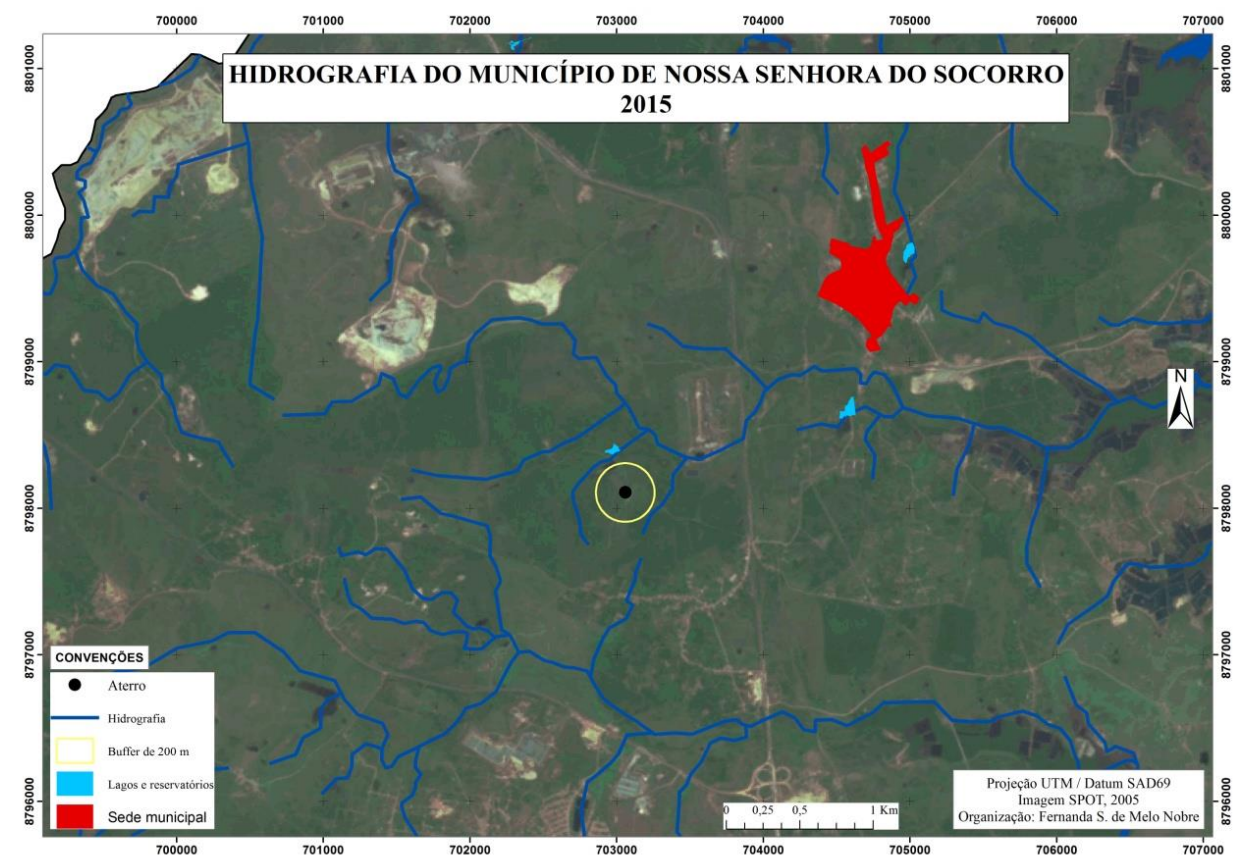

Figura 14: Mapa da hidrografia do município de Nossa Senhora do Socorro, Sergipe, destacando o buffer de 200 m que corresponde ao limite mínimo entre o aterro e corpos d'água do seu entorno. Fonte: SRH e SEMARH (2014) [15].

Para implementação de aterros sanitários é exigido que eles apresentem um distanciamento de $2000 \mathrm{~m}$ em relação à sede municipal para evitar possíveis incômodos à população urbana causados por odores e prevenir possíveis vetores de doenças [4]. Sendo assim, pode-se verificar, com base nas Figuras 15 e 16, que ambos os aterros encontram-se a uma distância menor que o 
critério de distanciamento exigido, sendo estas localizações, quanto a este fator, inapropriadas para a construção de aterros.

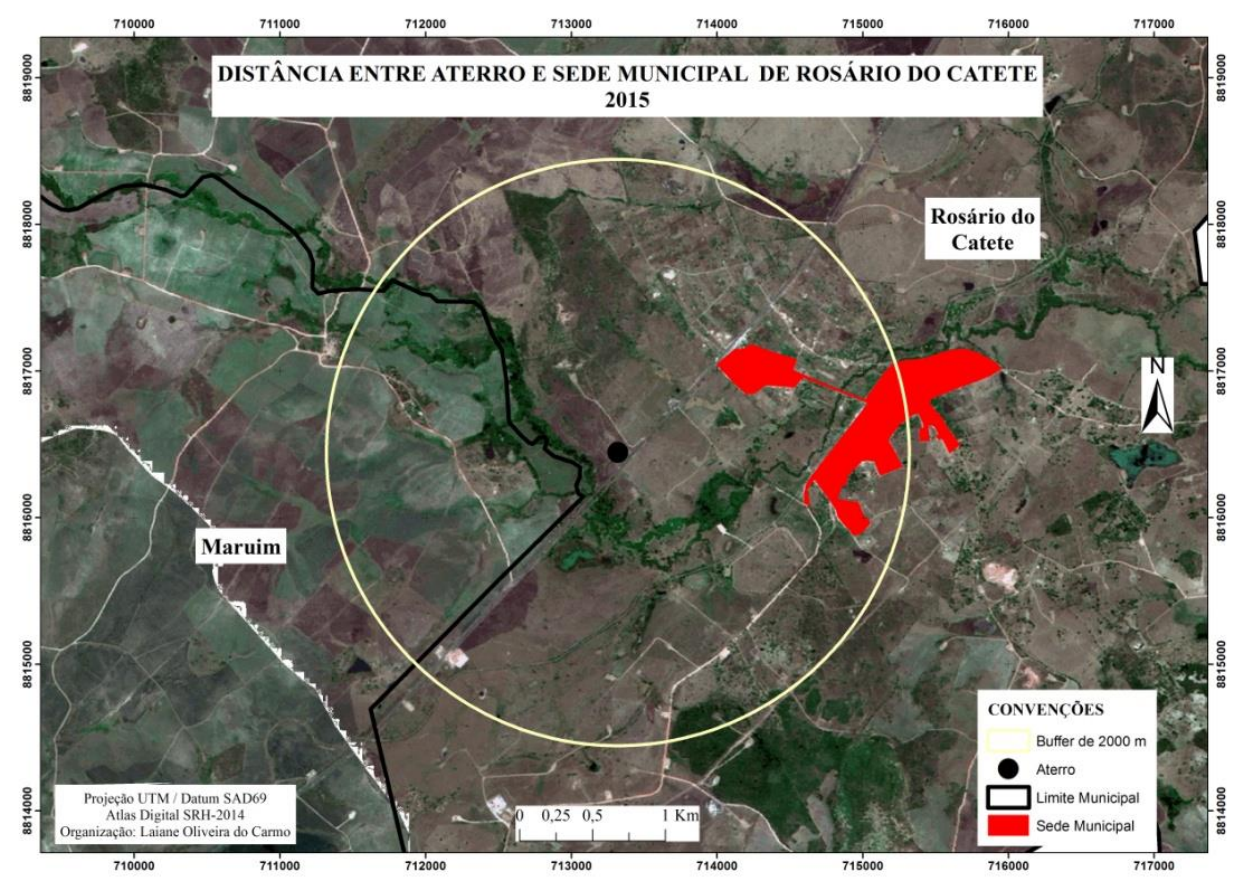

Figura 15: Mapa da distância entre o aterro e a sede municipal de Rosário do Catete, Sergipe, destacando o limite mínimo de $2000 \mathrm{~m}$ entre o aterro e dos centros urbanos. Fonte: SRH e SEMARH (2014) [15].

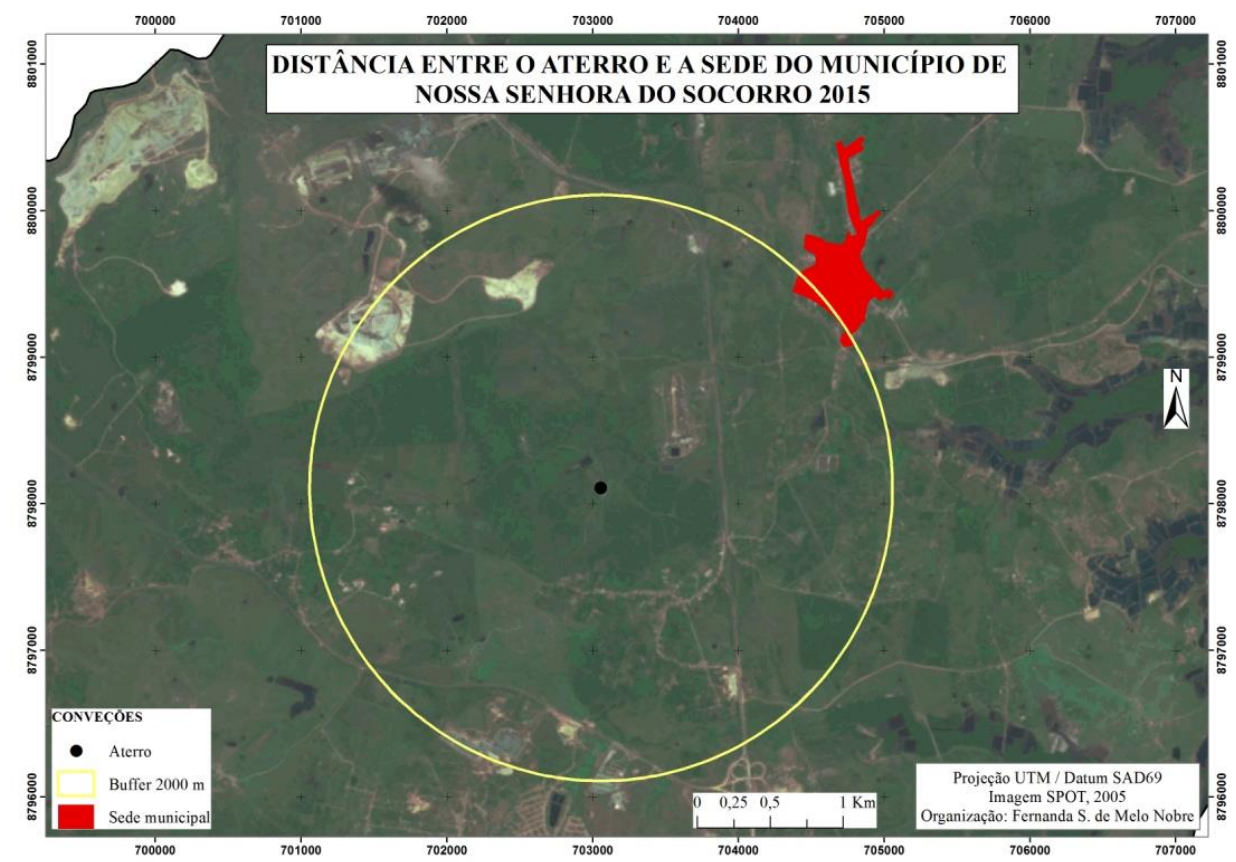

Figura 16: Mapa da distância entre o aterro e a sede municipal de Nossa Senhora do Socorro, Sergipe, destacando o limite mínimo de 2000 m entre o aterro e dos centros urbanos. Fonte: SRH e SEMARH

(2014) [15].

\section{CONCLUSÃO}

A partir dos resultados obtidos, utilizando as ferramentas de geoprocessamento nas análises para a confirmação da viabilidade da construção dos aterros sanitários do Centro de 
Gerenciamento de Resíduos Rosário do Catete e do Polo de Gerenciamento de Resíduos Itacanema, observou-se que a partir da base de dados do Atlas digital as análises, em relação aos critérios avaliados, foram satisfatórias. Entretanto, constatou-se que houve a não adequabilidade na escolha do local para a instalação de ambos os aterros quanto ao distanciamento do raio de $2000 \mathrm{~m}$ em relação à sede municipal, podendo provocar desconforto à população urbana quanto a odores gerados por esta atividade e possíveis vetores de doenças. Nesse sentido, as ferramentas de geoprocessamento são fundamentais na avaliação e definição de áreas destinadas a construção de aterros sanitários para garantir a preservação do meio ambiente e a proteção à saúde pública.

\section{REFERÊNCIAS BIBLIOGRÁFICAS}

1. Associação Brasileira de Empresas de Limpeza Pública e Resíduos Especiais (ABRELPE). Panorama dos resíduos sólidos no Brasil, 2014 [Internet]. Brasil: Associação Brasileira de Empresas de Limpeza Pública e Resíduos Especiais (ABRELPE); 2014 [citado 2015 Mai 10]. 120 p. Disponível em: http://www.abrelpe.org.br/Panorama/panorama2014.pdf. Acesso em: 10 de mai de 2015.

2. Associação Brasileira de Normas Técnica (ABNT). NBR 10004: resíduos sólidos - classificação. 2 ed. $2004.71 \mathrm{p}$.

3. Associação Brasileira de Normas Técnica (ABNT). NBR 13896: aterros de resíduos não perigososcritérios para projeto, implantação e operação. 1997.12 p.

4. Boscov GME. Geotecnia ambiental. 1 ed. São Paulo: Oficina de Textos; 2008. 249 p.

5. Centro de gerenciamento de resíduos Rosário do Catete [fotografia]. Rosário do Catete; [publicador desconhecido]; [data desconhecida]. 1 fotografia: colorida. Disponível em: http://www.grupos.com.br/group/fonasc.cbh/Messages.html?action=message \&id=1366565383242342 \&year $=13 \&$ month $=4 \&$ prev $=1$. Acesso em: 05 de mai de 2015.

6. D'almeida MLO, Vilhena A. Lixo municipal: manual de gerenciamento integrado. 2 ed. São Paulo: Instituto de Pesquisas Tecnológicas (IPT), Compromisso Empresarial para Reciclagem (CEMPRE); 2000.

7. Empresa Brasileira de Pesquisa Agropecuária (EMBRAPA). Brasil em Relevo. Disponível em: http://www.relevobr.cnpm.embrapa.br/download/index.htm. Acesso em: 14 de mai de 2015.

8. Instituto Brasileiro de Geografia e Estatística (IBGE). Estimativas da população residente no Brasil e unidades da federação com data de referência em $1^{\circ}$ de julho de 2015 [Internet]. Brasil: Diretoria de Pesquisas (DPE), Coordenação de População e Indicadores Sociais (COPIS); 2015 Out 28 [atualizado 2016 Jan 11$]$. $127 \quad$ p. $\quad$ Disponível [ em: ftp://ftp.ibge.gov.br/Estimativas_de_Populacao/Estimativas_2015/estimativa_2015_TCU_20160211.p df. Acesso em: 01 de mai de 2015.

9. Jacomin PKT. A nova classificação brasileira de solos. Anais da Academia Pernambucana de Ciência Agronômica. 2009; 5 e 6: 161-179.

10. Brasil. Lei $\mathrm{n}^{\circ} 12.305$ de 02 de agosto de 2010. [Internet]. Disponível em: http://www.planalto.gov.br/ccivil_03/_ato2007-2010/2010/lei/112305.htm. Acesso em: 14 de mai de 2015.

11. Ministério do Meio Ambiente [Internet]. Política de Resíduos Sólidos apresenta resultados em 4 anos; 11 agosto de 2014 [citado em 6 de Junho de 2016]. Disponível a partir de: http://www.mma.gov.br/informma/item/10272-pol\%C3\%ADtica-de-res\%C3\%ADduoss\%C3\%B3lidos-apresenta-resultados-em-4-anos. Acesso em: 11 de maio de 2015.

12. Organização das Nações Unidas (ONU). Programa da ONU para o meio ambiente alerta para o problema da gestão dos resíduos no mundo, mas aponta que esta pode se tornar uma área modelo para a economia verde [Internet]. Brasil; 2012 Nov 6 [atualizado 2012 Nov 6]. Disponível em: https://nacoesunidas.org/volumederesiduosurbanoscrescerade13bilhaodetoneladaspara22bilhoesate20 25dizpnuma/. Acesso em: 14 de mai de 2015.

13. Polo de gerenciamento de resíduos Itacanema [fotografia]. Nossa Senhora do Socorro; [publicador desconhecido]; [data desconhecida]. 1 fotografia: colorida. Disponível em: https://www.google.com.br/url?sa=i\&rct=j\&q=\&esrc=s\&source=images\&cd=\&ved=0ahUKEwiVtPS uhJTNAhXMRyYKHSDxATAQ5TUICQ\&url=http\%3A\%2F\%2Fwww.adema.se.gov.br\%2Fmodules \%2Fwfdownloads\%2Fvisit.php\%3Fcid\%3D1\%26lid\%3D509\&bvm=bv.123664746,d.cWw\&psig=AF QjCNFq4EikWJBjXidTq7J3floYON9Y1w\&ust=1465324244953370. Acesso em: 07 de mai de 2016.

14. Souza SS, Teixeira GF. Aterro Sanitário: Um problema de Cruz das Almas. Revista NAU Social. 2012 Mai; 3(4):29-37. 
15. Superintendência de Recursos Hídricos (SRH), Secretaria de Estado do Meio Ambiente e dos Recursos Hídricos (SEMARH). Atlas digital sobre recursos hídricos de Sergipe: sistema de informações sobre recursos hídricos de Sergipe (SIRHSE) [CD-ROM]. Aracaju: Superintendência de Recursos Hídricos (SRH); Secretaria de Estado do Meio Ambiente e dos Recursos Hídricos (SEMARH). 2014. CD-ROMs: 4 3/4 in. 